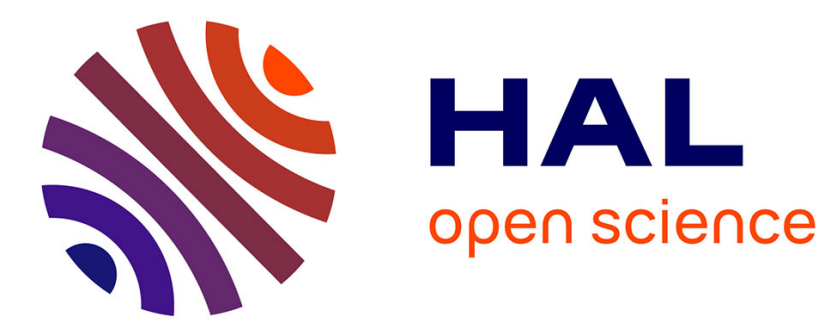

\title{
Unexpected fast development of branched broomrape on slow-growing Brassicaceae
}

Stéphanie Gibot-Leclerc, Carole Reibel, Valérie Le Corre, Fabrice Dessaint

\section{To cite this version:}

Stéphanie Gibot-Leclerc, Carole Reibel, Valérie Le Corre, Fabrice Dessaint. Unexpected fast development of branched broomrape on slow-growing Brassicaceae. Agronomy for Sustainable Development, 2015, 35 (1), pp.151-156. 10.1007/s13593-014-0217-6 . hal-01284245

\section{HAL Id: hal-01284245 \\ https://hal.science/hal-01284245}

Submitted on 7 Mar 2016

HAL is a multi-disciplinary open access archive for the deposit and dissemination of scientific research documents, whether they are published or not. The documents may come from teaching and research institutions in France or abroad, or from public or private research centers.
L'archive ouverte pluridisciplinaire HAL, est destinée au dépôt et à la diffusion de documents scientifiques de niveau recherche, publiés ou non, émanant des établissements d'enseignement et de recherche français ou étrangers, des laboratoires publics ou privés.

$$
\text { Copyright }
$$




\title{
Unexpected fast development of branched broomrape on slow-growing Brassicaceae
}

\author{
Stéphanie Gibot-Leclerc • Carole Reibel • \\ Valérie Le Corre • Fabrice Dessaint
}

Accepted: 21 February 2014 / Published online: 28 March 2014

(C) INRA and Springer-Verlag France 2014

\begin{abstract}
In France, oilseed rape is getting highly infected since 1990 by the branched broomrape Phelipanche ramosa (L.) Pomel. Branched broomrape infection causes serious yield losses ranging from 5 to $100 \%$, notably in the Mediterranean area. P. ramosa is parasiting the plant roots. The growth of $P$. ramosa on Brassicaceae weeds has not been studied quantitatively so far, except for the model species Arabidopsis thaliana. Since $P$. ramosa has a fast development rate on the fast-growing A. thaliana, P. ramosa development should be slower on other slower-growing Brassicaceae species. Here, we cultivated in the laboratory seven Brassicaceae weed species including Capsella bursa-pastoris, Capsella rubella, Cardamine hirsuta, Lepidium campestre, Lepidium draba, Sinapis arvensis and A. thaliana as control, during 3 weeks. We counted the number of $P$. ramosa individuals that have reached the following growth stages: germination, attachment, tubercle, bud and underground stem. We then assessed the development rate of $P$. ramosa by calculating the odds ratio of attachment or higher development stages of P. ramosa on Brassicaceae, with A. thaliana as the reference. We found that five Brassicaceae species had an odds ratio ranging from 0.9 to 2.4 . These ratios are thus similar or higher than that of the $A$. thaliana reference. This finding shows for the first time that $P$. ramosa develops faster on the five Brassicaceae species. This finding is also unexpected because A. thaliana is a fast-growing plant, whereas the five
\end{abstract}

S. Gibot-Leclerc $\cdot$ C. Reibel

AgroSup Dijon, UMR1347 Agroécologie, 21000 Dijon, France

V. Le Corre $\cdot$ F. Dessaint

INRA, UMR1347 Agroécologie, 21000 Dijon, France

S. Gibot-Leclerc $(\square)$

Département Agronomie Agroéquipement Elevage Environnement,

AgroSup Dijon, UMR1347 Agroécologie, 26 Bd Dr Petitjean, BP

87999-21 079 Dijon Cedex, France

e-mail: stephanie.gibot-leclerc@dijon.inra.fr
Brassicaceae species have a longer life cycle. Therefore, this observation demonstrates for the first time that P. ramosa development depends on others factors than the speed of plant host development.

Keywords Phelipanche ramosa Parasitic plant . Arabidopsis thaliana $\cdot$ Capsella $\cdot$ Cardamine $\cdot$ Lepidium . Sinapis

\section{Introduction}

Among flowering plants, approximately 3,000 species (1\%) are parasitic. These parasitic plants form a close connection with the vascular system of their host plant through a specialised organ, the haustorium, through which they remove water, mineral salts and carbon elements (Parker and Riches 1993; Press and Graves 1995). Branched broomrapePhelipanche ramosa (L.) Pomel (syn. Orobanche ramosa) is a root-holoparasitic angiosperm known to be the cause of crop losses ranging from 5 to $100 \%$, particularly in countries surrounding the Mediterranean basin (Parker 2009; Press and Phoenix 2005). In Central Europe, populations have mainly infested tobacco (Nicotiana tabacum L., Solanaceae) and hemp (Cannabis sativa L., Cannabinaceae) fields (Buschmann et al. 2005). In France, oilseed rape (Brassica napus L., Brassicaceae) is a new preferred P. ramosa host, with a massive extension of the parasite since the beginning of the 1990s and yield losses over $80 \%$ (Gibot-Leclerc et al. 2003, 2012, 2013a). This crop has even become the primary host for the parasite, along with $C$. sativa and $N$. tabacum (Benharrat et al. 2005; Brault et al. 2007). Several authors reported a fine-tuning between the host crop and parasite development cycles, depending on the host species considered, with a corresponding adjustment of growth and an ability to adjust flowering according to the amount of 
resources gained from the host (Brault et al. 2007; GibotLeclerc et al. 2012; Kogan 1994; Labrada 1994).

Phelipanche ramosa can also infect more than 70 weed species in B. napus fields strongly infested by the parasite and thus persist and even proliferate in the absence of host crops (Boulet et al. 2001; Gibot-Leclerc et al. 2003, 2013b). Numerous Brassicaceae weed species are known to be both infected by $P$. ramosa and abundant within $B$. napus fields since herbicides selective for oilseed rape have a low efficacy on these closely related species (Fried and Reboud 2007; Gibot-Leclerc et al. 2003). Among Brassicaceae weeds, thale cress (Arabidopsis thaliana (L.) Heynh.) is widely used as a useful model for the study of plant biology, including plantplant interactions (Mienke et al. 1998; Goldwasser et al. 2002; Bouwmeester et al. 2003). P. ramosa infection on A. thaliana is similar to that on agricultural hosts. However, the parasite developing on $A$. thaliana has a proportionally faster development rate (45 days) and smaller size at maturity (1-4 flowers) than $P$. ramosa developing on host crops (Goldwasser and Yoder 2001; Goldwasser et al. 2002, 2008; Neumann and Sallé 2000). The dynamics of growth and development of P. ramosa on other Brassicaceae weeds has not been described so far. In this study, we analyse how fast P. ramosa can grow and develop on representative Brassicaceae weeds, in comparison to $A$. thaliana. Our results provide new insights about the likely influence of Brassicaceae weeds on the parasite extension in B. napus fields.

\section{Materials and methods}

\subsection{Seed material}

Parasite seeds were collected from natural populations of P. ramosa that had severely infested tobacco fields in Priaires ( $46^{\circ} 08^{\prime} 31^{\prime \prime} \mathrm{N}, 00^{\circ} 36^{\prime} 24^{\prime \prime} \mathrm{W}$; Deux-Sèvres, France) in 2002. Once harvested, the seeds were sifted for cleaning. We chose to study the development of P. ramosa on six Brassicaceae weed species that are commonly found in oilseed rape fields (Fried and Reboud 2007; Gibot-Leclerc et al. 2003): shepherd's purse (Capsella bursa-pastoris (L.) Medik.), red shepherd's purse (Capsella rubella Reut.), hairy bittercress (Cardamine hirsuta L.), field pepperweed (Lepidium campestre (L.) R. Br.), whitetop (Lepidium draba L.) and wild mustard (Sinapis arvensis L.). A. thaliana was included as a control since it was previously used to study the germination, haustorium development and growth of $P$. ramosa under controlled conditions (Goldwasser and Yoder 2001; Goldwasser et al. 2002, 2008; Neumann and Sallé 2000). Seeds of the seven Brassicaceae were bought from the seed company Herbiseed in 2010. After collection, all seeds were kept in watertight glass containers at room temperature (approximately $20^{\circ} \mathrm{C}$ ) until the beginning of the experiments.

\subsection{In vitro experiments}

After disinfection, 75-100 seeds of P. ramosa were laid on Whatman GF/A paper discs (Ø $12 \mathrm{~mm}$ ). Five discs prepared that way were placed on a Whatman GF/A paper sheet (Ø $90 \mathrm{~mm}$ ) at the bottom of a Petri dish (Ø $90 \mathrm{~mm})$, and then hydrated. Three Petri dishes, containing 375-500 seeds each, were placed in darkness at $20^{\circ} \mathrm{C}$ for 14 days to pre-condition the seeds. Thereafter, three disinfected Brassicaceae weed seeds were placed in a rectangular plastic box containing MS (1/2) (Murashige and Skoog 1962) nutrient solution with $1 \%$ agar. The box prepared that way was placed in a growth chamber, at $23 \pm 1{ }^{\circ} \mathrm{C}$ (day) and $18 \pm 1{ }^{\circ} \mathrm{C}$ (night), with a 16-h photoperiod and $70 \mathrm{~mol} \mathrm{~m}^{-2} \mathrm{~s}^{-1}$ photosynthetic photon flux density (PPFD). Once the Brassicaceae weed root system had developed (i.e. 2 weeks after the beginning of the experiment), the five discs bearing the pre-conditioned P. ramosa seeds were transferred under the host root system. The P. ramosal Brassicaceae weed co-cultivation was carried out in the same temperature and light conditions (Fig. 1). The development of the infected Brassicaceae weed roots was assessed 3 weeks later under a stereo microscope. The pre-emergent ontogenic stages of the parasite on Brassicaceae weed hosts were recorded. The development of the parasite was thus described by counting the number of individuals having reached the following pre-emergent ontogenic stages according to GibotLeclerc et al. (2012): germination, attachment on host root, young tubercle, old tubercle, bud and underground stem. The experiment was performed for all the seven Brassicaceae weed species. For each species, the experiment was repeated three times in exactly the same experimental conditions, starting on January 17, 2011. In total, three boxes were thus prepared per plant species, each containing three plants and five paper discs with 75-100 parasite seeds per disc, resulting in a total of 45 parasite discs and approximately 3,900 parasite seeds per plant species.

\subsection{Data analysis}

For each species, we calculated the odds. The 'odds' of an event are defined as the probability of the outcome event occurring $(p)$ divided by the probability of the event not occurring $(1-p)$. In this case, $p$ was the probability of the $P$. ramosa stage being "attachment" or higher and $1-p$, the probability of $P$. ramosa stage being "germination". Then we calculated the odds ratios (ORs) with A. thaliana as the reference and their $95 \%$ confidence intervals. An odds ratio of less than 1 indicates that the probability to reach "attachment" or higher stages is more likely in the A. thaliana species, whilst an odds ratio greater than 1 indicates that the probability is more likely in the other weed species. All analyses were done with $\mathrm{R}$ version 3.0.1 ( $\mathrm{R}$ Development Core Team 2013). 
Brassicaceae seeds germination

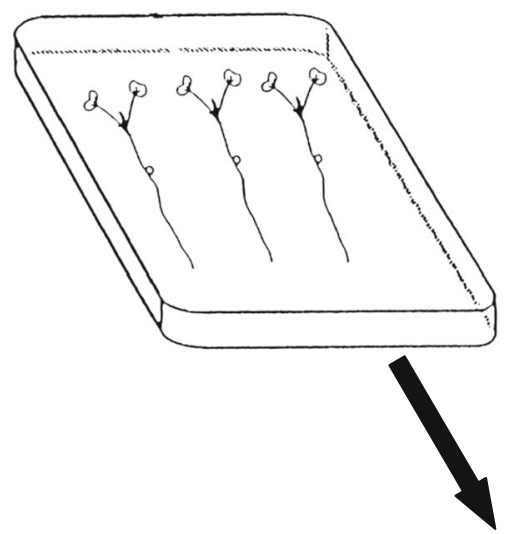

\section{P. ramosa/Brassicaceae weed co-cultivation}

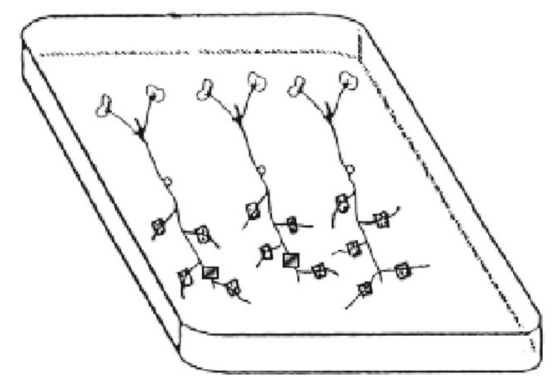

Fig. 1 Co-culture in vitro experiment to study P. ramosa infection on Brassicaceae weeds. After disinfection, 75-100 seeds of $P$. ramosa were laid on paper discs. Five discs prepared that way were placed on a paper sheet at the bottom of a Petri dish, and then hydrated. Three Petri dishes, containing 375-500 seeds each, were placed in darkness at $20^{\circ} \mathrm{C}$ for 14 days to pre-condition the seeds. Thereafter, three disinfected Brassicaceae weed seeds were placed in a rectangular plastic box containing MS $(1 / 2)$ nutrient solution with $1 \%$ agar. The box prepared that way was placed in a growth chamber, at $23 \pm 1{ }^{\circ} \mathrm{C}$ (day) and $18 \pm 1^{\circ} \mathrm{C}$ (night), with a 16-h photoperiod and $70 \mathrm{~mol} \mathrm{~m} \mathrm{~s}^{-1}$ PPFD. Once the Brassicaceae

\section{Results and discussion}

We described the advancement of pre-emergent ontogenic stages of $P$. ramosa based on our controlled experiments associating parasite seeds with the root system of seven Brassicaceae weed root system had developed (i.e. 2 weeks after the beginning of the experiment), the five discs bearing the pre-conditioned $P$. ramosa seeds were transferred under the host root system. The $P$. ramosa/Brassicaceae weed co-cultivation was carried out in the same temperature and light conditions. The development of the infected Brassicaceae weed roots was assessed 3 weeks later under a stereo microscope. The pre-emergent ontogenic stages of the parasite on Brassicaceae weed hosts were recorded. The development of the parasite was thus described by counting the number of individuals having reached the following pre-emergent ontogenic stages according to Gibot-Leclerc et al. (2012)

species. The development observed on six weeds was compared with that observed on the model plant $A$. thaliana.

All Brassicaceae weed species induced germination and subsequent attachment of $P$. ramosa on their roots (Table 1). After 3 weeks, the odds of attachment or higher stages were
Table 1 Numbers of $P$. ramosa plants for each of the five underground ontogenic stages observed on Brassicaceae weed root systems after the 3-week in vitro experiment. Plant species are sorted top to bottom according to P. ramosa speed of development

\begin{tabular}{|c|c|c|c|c|c|c|}
\hline \multirow[t]{2}{*}{ Brassicaceae weeds species } & \multicolumn{6}{|c|}{ Phelipanche ramosa ontogenic developmental stages } \\
\hline & Attachment & $\begin{array}{l}\text { Young } \\
\text { tubercule }\end{array}$ & $\begin{array}{l}\text { Old } \\
\text { tubercule }\end{array}$ & Bud & $\begin{array}{l}\text { Underground } \\
\text { stem }\end{array}$ & Total \\
\hline Capsella bursa-pastoris & 58 & & 1 & 1 & 5 & 65 \\
\hline Capsella rubella & 35 & & 2 & 2 & & 39 \\
\hline Lepidium campestre & 26 & & & 1 & & 27 \\
\hline Cardamine hirsuta & 65 & & 2 & & & 67 \\
\hline Sinapis arvensis & 0 & & 2 & & & 2 \\
\hline Arabidopsis thaliana & 40 & & & & & 40 \\
\hline Lepidium draba. & 15 & & & & & 15 \\
\hline
\end{tabular}


Fig. 2 Odds ratios and $95 \%$ confidence interval (A. thaliana as reference). An odds ratio equal to 1 indicates that the probability to reach "attachment" or higher stages is equally likely in the two species. An odds ratio greater than 1 indicates that the probability is more likely in the other weed species and an odds ratio lesser than 1 indicates that the probability is more likely in A. thaliana. The red line indicates $\mathrm{OR}=1$. We found that five Brassicaceae species had an odds ratio ranging from 0.9 to 2.4 . These ratios are thus similar or higher than that of the $A$. thaliana reference. This finding shows for the first time that $P$. ramosa develops faster on the five Brassicaceae species

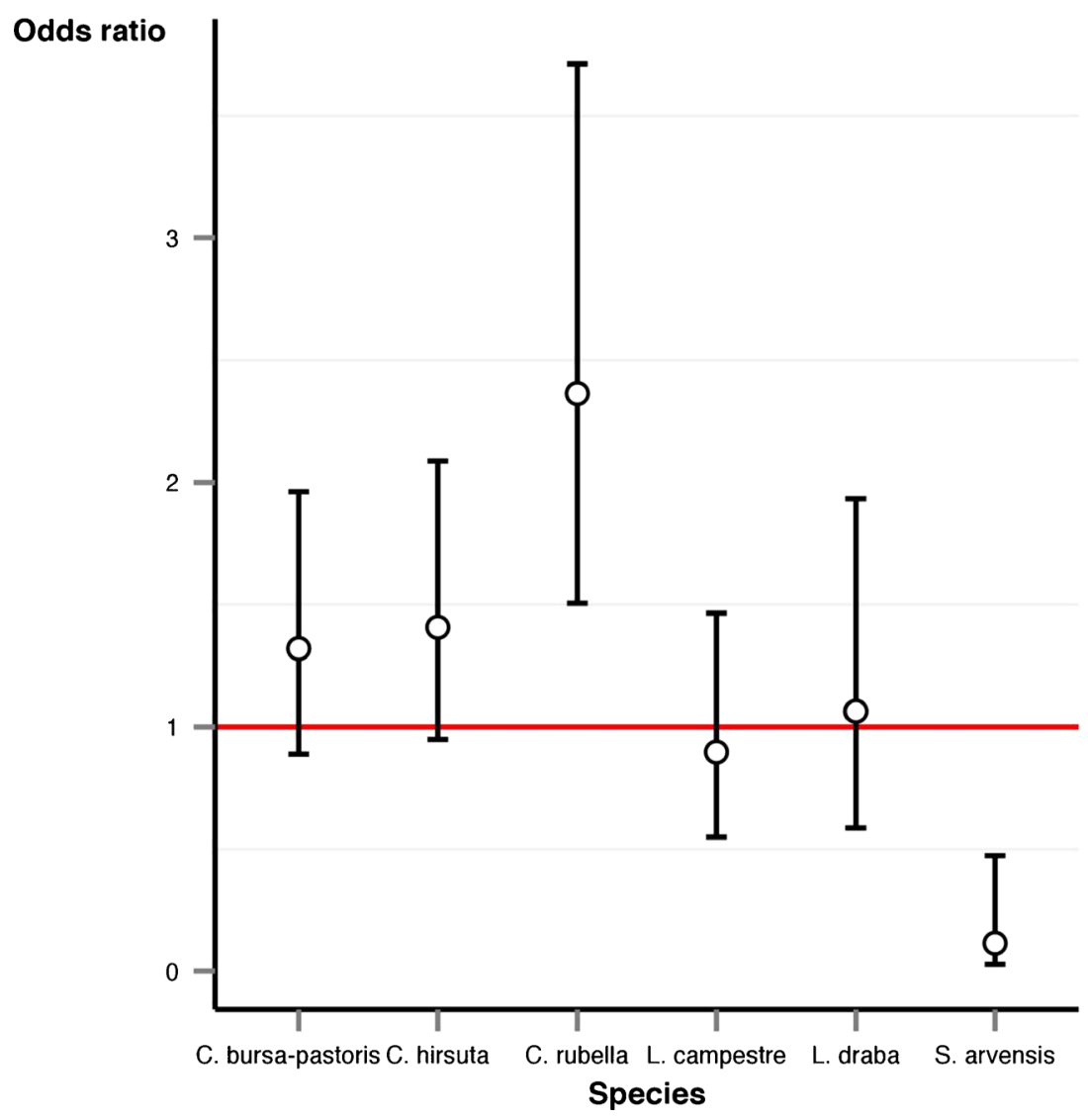

$1.1 \%$ for A. thaliana, $1.2 \%$ for L. draba, $1.5 \%$ for Capsella bursa-pastoris, $2.6 \%$ for Capsella rubella, $1.6 \%$ for Cardamine hirsuta, $1.0 \%$ for L. campestre and $0.1 \%$ for $S$. arvensis. Our experiments thus confirmed that $P$. ramosa is able to infect the seven Brassicaceae species tested. The ratio of the number of fixations or higher stages to the number of germinated seeds was similar between the Brassicaceae weeds and A. thaliana, except for Capsella rubella, which showed a significantly higher ratio and $S$. arvensis, which showed a significantly smaller ratio (Fig. 2). Records of the ontogenic stages observed during 3 weeks revealed that the rate of development of the parasitic plant was as fast or faster on each of the studied weed species than it was on A. thaliana. For all species except $L$. draba (Table 1), we observed more advanced stages such as 'old tubercle' (on Cardamine hirsuta and S. arvensis), 'bud' (on Capsella rubella and L. campestre) and even 'underground stem' (on Capsella bursa-pastoris). These stages were not present in A. thaliana.

The observation that all the Brassicaceae species studied could be infected by P. ramosa is consistent with the known host range of the parasite on agricultural crops: oilseed rape (B. napus), brown mustard (Brassica juncea), cabbage (Brassica oleracea) and white mustard (Sinapis alba) are all susceptible to it (Foy et al. 1989; Parker and Riches 1993). Concerning Brassicaceae weeds, infection by P. ramosa has been reported for Capsella bursa-pastoris, Cardamine hirsuta, L. draba and
S. arvensis (Boulet et al. 2001; Gibot-Leclerc et al. 2009). Our study is the first to report infection of Capsella rubella and $L$. campestre by P. ramosa. The faster rates of development observed on weed species, and especially on Capsella sp., as compared to $A$. thaliana were surprising given that all these species have longer life cycle duration than the fast-growing A. thaliana. For example, under favourable long-day conditions the flowering time for Capsella bursa-pastoris varies between 36 and 200 days (Ceplitis et al. 2005), while under the same

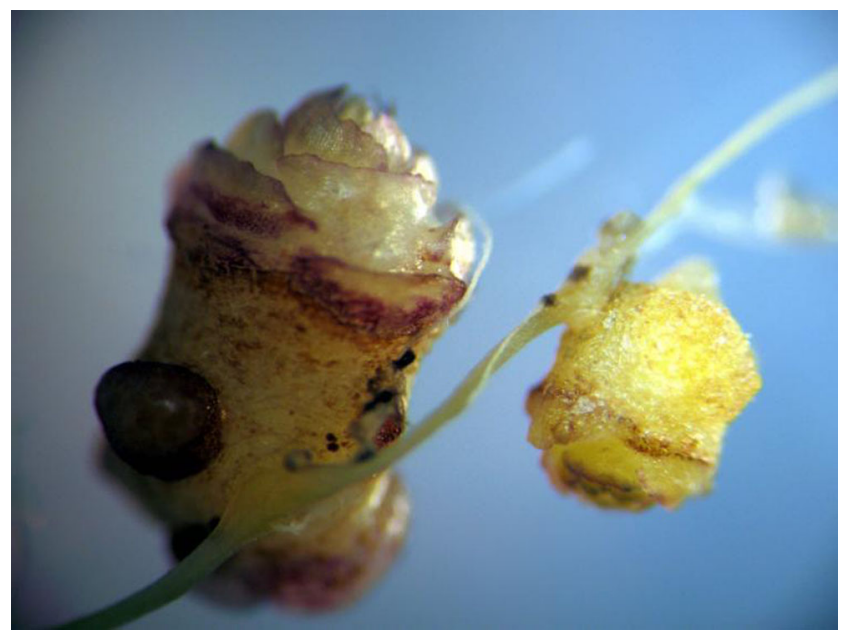

Fig. 3 Reduced underground stem of P. ramosa as developed on C. bursa-pastoris roots. Magnification $\times 33$ 
conditions, the 'rapid-cycling' $A$. thaliana ecotype Col-0 flowers in only 32 days (Boyes et al. 2001). Our results thus indicate that the speed of development of the parasitic plant does not strictly depend on the speed of development of its host but also on other factors, such as the amount of resources that can be obtained from the host. In any case, our results suggest that P. ramosa is able to rapidly complete its life cycle on various Brassicaceae weeds. This rapid development is, however, associated with a much reduced size (Fig. 3) and, as a consequence, a much reduced seed production. One can therefore question what influence the presence of Brassicaceae weeds might have on the population dynamics of $P$. ramosa within cultivated environments. Noticeably, many Brassicaceae weeds are particularly common and ubiquitous within agricultural landscapes. For example, Capsella sp. is able to develop within cultivated fields as well as within various uncultivated habitats, including the crop edges and field boundaries. Moreover, Capsella sp. seeds can germinate throughout the year and up to three generations can be observed within a single year (Aksoy et al. 1998). Capsella sp. and similar Brassicaceae weeds are therefore commonly observed during inter-cropping. Thus, the fast development and low seed output associated with fixation on those weeds can be compensated for by a higher probability of survival of the parasitic plants, as they escape the management practices implemented within crops.

\section{Conclusion}

Our present work confirms that the parasitic plant is able to infect various weedy species that belong to the Brassicaceae family and commonly occur within B. napus fields. Importantly, our results reveal that the rate of development of P. ramosa is faster on these species than it is on the fastgrowing plant $A$. thaliana. We therefore suggest that more attention should be paid to the role of Brassicaceae weeds that grow besides or after the crops as alternative hosts and to their importance for the demography of $P$. ramosa.

Acknowledgments The present work was financed by AgroSup Dijon and INRA, (ANR-07-POGM-003-01) and the Regional Action Plan for Innovation (PARI 2010-9201AAO050S01397).

\section{References}

Aksoy A, Dixon JM, Hale WHG (1998) Capsella bursa-pastoris (L.) Medikus. (Thlaspi bursa-pastoris (L.), Bursa bursa-pastoris (L.) Schull, Bursa pastoris (L.) Weber). J Ecol 86:171-186

Benharrat H, Boulet C, Theodet C, Thalouarn P (2005) Virulence diversity among branched broomrape $(O$. ramosa $\mathrm{L}$.) populations in France. Agron Sustain Dev 25:123-128

Boulet C, Labrousse P, Arnaud MC, Zehhar N, Fer A (2001) Weed species present various responses to Orobanche ramosa. In: Proceedings of the Seventh International Parasitic Weed Symposium. Faculté des Sciences de Nantes. 228-231. Nantes, France

Bouwmeester HJ, Matusova R, Zhongkui S, Beale MH (2003) Secondary metabolite signalling in host-parasitic plant interactions. Curr Opin Plant Biol 6:358-364

Boyes D, Zayed AM, Ascenzi R et al (2001) Growth-stage based phenotypic analysis of Arabidopsis: a model for high throughout functional genomics in plants. Plant Cell 13:1499-1510

Brault M, Betsou F, Jeune B, Tuquet C, Sallé G (2007) Variability of Orobanche ramosa populations in France as revealed by cross infestations and molecular markers. Environ Exp Bot 67:271-280

Buschmann H, Gonsior G, Sauerborn J (2005) Pathogenecity of branched broomrape (Orobanche ramosa) populations on tobacco cultivars. Plant Pathol 54:650-656

Ceplitis A, Su Y, Lascoux M (2005) Bayesian inference of evolutionary history from chloroplast microsatellites in the cosmopolitan weed Capsella bursa-pastoris (Brassicaceae). Mol Ecol 14:4221-4233

Foy CL, Jain R, Jacobsohn R (1989) Recent approaches for chemical control of broomrape (Orobanche spp.). Rev Weed Sci 4:123-152

Fried G, Reboud X (2007) Evolution de la composition des communautés adventices des cultures de colza sous l'influence des systèmes de culture. OCL 14:130-138

Gibot-Leclerc S, Brault M, Pinochet X, Sallé G (2003) Potential role of winter rape weeds in the extension of broomrape in PoitouCharentes. C R Biol 326:645-658

Gibot-Leclerc, S., Charles, J., Dessaint, F., 2009. Potential host plant susceptibility to two Orobanche ramosa L. races. In: XIIIe Colloque International sur la Biologie des Mauvaises Herbes, Dijon, France, pp. 446-456.

Gibot-Leclerc S, Sallé G, Reboud X, Moreau D (2012) What are the traits to Phelipanche ramosa (L.) Pomel that contribute to the success of its biological cycle on its host Brassica napus L. ? Flora 207:512-521

Gibot-Leclerc S, Reibel C, Dessaint F, Le Corre V (2013a) Phelipanche ramosa (L.) Pomel populations differ in life-history and infection response to hosts. Flora 208:247-252

Gibot-Leclerc S, Abdennebi-Abdemessed N, Reibel C, Colbach N (2013b) Non host-facilitators, a new category that unexpectedly favours parasitic weeds. Agron Sustain Dev 33: 787-793

Goldwasser Y, Yoder JI (2001) Differential induction of Orobanche seed germination by Arabidopsis thaliana. Plant Sci 160:951-959

Goldwasser Y, Westwood JH, Yoder JI (2002) The use of Arabidopsis to study interactions between parasitic angiosperms and their plant hosts. The Arabidopsis Book. American Society of Plant Biologists

Goldwasser Y, Yoneyama K, Xie X, Yoneyama K (2008) Production of strigolactones by Arabidopsis thaliana responsible for Orobanche aegyptiaca seed germination. Plant Growth Regul 55:21-28

Kogan M (1994) Orobanche in Chile: a research report. In: Biology and Management of Orobanche. Proc. 3rd Int. Workshop on Orobanche and related Striga Res. Roy. Trop. Inst. Amsterdam, pp. 599-603

Labrada R (1994) Occurrence and control of Orobanche ramosa L. in Cuba. In: Biology and Management of Orobanche. Proc. 3rd Int. Workshop on Orobanche and related Striga Res. Roy. Trop. Inst. Amsterdam, pp. 604-610

Mienke DW, Cherry JM, Dean C, Rounsley SD, Koomneef M (1998) Arabidopsis thaliana: a model plant for genome analysis. Science 282:662-682

Neumann U, Sallé G (2000) Defense mechanisms of plants against parasitic angiosperms. CR Acad Agric Fr 86:85-96 
Parker C (2009) Observations on the current status of Orobanche and Striga problems worldwide. Pest Manag Sci 65:453-459

Parker C, Riches CR (1993) Parasitic weeds of the world: biology and control. CAB International, Wallingford, UK

Press MC, Graves JD (1995) Parasitic plants. Chapman and Hall, London
Press MC, Phoenix GK (2005) Impacts of parasitic plants on natural communities. New Phytol 166:737-751

R Core Team (2013) R: A language and environment for statistical computing. R Foundation for Statistical Computing, Vienna, Austria (http://www.R-project.org/) 